\title{
Estrategia de evaluación innovadora: Programa de Ciudadanía Plena en Política Urbana Inteligente
}

\section{Resumen}

\author{
Ferrer, Mercedes ${ }^{\star}$ \\ Gómez, Nersa** \\ Reyes, Ramón***
}

El artículo presenta la estrategia diseñada para evaluar el potencial de transformación del Programa Ciudadanía Plena (PCP) en política urbana inteligente. La evaluación se realiza a partir del análisis del modelo de gestión implantado en Maracaibo (Venezuela), que integra actores públicos, privados y comunitarios. EI PCP es un programa promovido inicialmente desde la Universidad del Zulia para superar la pobreza urbana actuando sobre la precariedad del hábitat y la ausencia de ciudadanía plena, mediante la formación ciudadana y el otorgamiento de microcréditos para mejorar el hábitat urbano -viviendas y crear o fortalecer microempresas-, contribuyendo al desarrollo local sostenible. El potencial transformador del PCP se establece a partir de las variables que caracterizan una política urbana inteligente: emponderamiento y cohesión ciudadana, legitimación del alcalde (desempeño), compromiso multiactoral y gobernabilidad. Dos conclusiones destacan de la investigación: la estrategia diseñada permitirá evaluar el grado de apropiación del PCP como esfuerzo colectivo, el logro de objetivos y proponer acciones para garantizar su permanencia en la agenda -aspectos que potencian su transformación en política-. EI PCP asumido como política urbana inteligente viabilizará la emergencia de una nueva "ciudadanía" fundada en valores y nuevas capacidades de gestión local -coordinación transversal multiactoral y multidisciplinar-, como vía hacia la sostenibilidad de Maracaibo y la superación de la pobreza urbana.

Palabras clave: Programa Ciudadanía Plena, política inteligente, pobreza urbana, evaluación estratégica.

Recibido: 05-12-23. Aceptado: 06-07-16

* Arquitecto, Master en Filosofía en Planificación Urbana-Regional (Newcastle University, Inglaterra), Doctora en Ciencia Política. Profesora de pre y postgrado e Investigadora Titular de la Facultad de Arquitectura y Diseño (FAD) y del Centro de Estudios de la Empresa de la Facultad de Ciencias Económicas y Sociales de la Universidad del Zulia. Miembro del Programa de Promoción al Investigador Nivel I. E-mail: mferrer_98@yahoo.com

** Arquitecto, Magíster en Educación, Profesora de pre y postgrado e Investigadora Titular de la Facultad de Arquitectura y Diseño (FAD), en el área de planificación urbana-ambiental y tecnología docente, de la Universidad del Zulia. E-mail: nersag@cantv.net

*** Arquitecto, Magíster en Arquitectura. Profesor de pre y postgrado e Investigador Asociado de la Facultad de Arquitectura y Diseño (FAD) en el área de Urbanismo.

E-mail: rareyesar@yahoo.es 
Estrategia de evaluación innovadora

Ferrer, Mercedes; Gómez, Nersa y Reyes, Ramón

\title{
Innovative Evaluation Strategy: From the Full Citizenship Program to Intelligent Urban Policy
}

\begin{abstract}
This article presents strategies designed to evaluate transformation potential of the Full Citizenship Program (FCP) in intelligent urban policy. The evaluation was made based on an analysis of the management model imposed in Maracaibo (Venezuela), which integrated public, private and community actors. The FCP is a program promoted initially in the University of Zulia in order to overcome urban poverty by acting on the precariousness of habitat and the absence of full citizenship, through citizenship formation and the granting of micro-credits in order to improve the urban-housing habitat, and to create and strengthen micro-businesses, contributing in this manner to sustainable local development. The potential FCP transformers were established based on the variables that characterize an intelligent urban policy: citizen empowerment and cohesion, legitimization of the functioning of the Mayors office, multi-actor participation, and govern-ability. Two conclusions stand out from this research: the strategy designed permitted an evaluation of the grade of appropriateness of the FCP as a collective action, the achievement of objectives, and the proposal of actions to guarantee its permanence in the agenda- all aspects which empower its transformation into policy. The FCP was assumed as an intelligent urban policy, to make viable the emergence of a new citizenry, based on values and new capacities of local management, and on multi-actor and multidisciplinary transversal coordination, and as a pathway to sustainability in Maracaibo and the overcoming of urban poverty.
\end{abstract}

Key words: Full Citizenship Program, intelligent policy, urban poverty, strategic evaluation.

\section{Introducción}

Venezuela no escapa a la situación de América Latina en relación con la pobreza, por un lado existe un crecimiento lento y por otro hay gran desigualdad que ha sumido en la pobreza estructural a gran parte de la población, siendo los problemas más graves, la exclusión social, la precariedad del hábitat y de ciudadanía, a lo que se suman escasas políticas que favorezcan la integración social y la participación. Según España (en Ugalde et al, 2004) coordinador del Proyecto Pobreza de la Universidad Católica Andrés Bello -UCAB- (Caracas, Venezuela) luego de 60 años de crecimiento (1918 a 1978) del PIB superior al $6 \%$ anual, de ascenso y movilidad social, Venezuela entró en des- censo desde hace veintiséis años y empezó a crecer la pobreza en forma sostenida y alarmante.

La tendencia y evolución de la pobreza en Venezuela en los últimos veintiséis años muestra para España (2004: 43-44), que ha aumentado de menos del $25 \%$ de los hogares en 1978 a representar para el año 2001 más del 60\% y los niveles de pobreza crítica en ese mismo periodo pasaron de menos del $10 \%$ a más del $30 \%$. Esta tendencia histórica muestra picos que se corresponden con los ciclos recesivos que la economía venezolana ha venido registrando desde 1989, asociados a los precios de la canasta petrolera. Durante el periodo 1979-2003, la economía venezolana mostró un pésimo desempeño para Es- 
paña, dado que en promedio presenta un crecimiento negativo de $-0,9 \%$. La ausencia de crecimiento económico y la correspondiente baja generación de empleos formales han hecho que las oportunidades laborales en Venezuela sean precarias. Según España (2006: 54) entre 2002 y 2003 la pobreza vuelve a crecer debido a la coyuntura del ajuste económico del año 2002 y posteriormente los eventos políticos de ese año y el 2003, los cuales ampliaron el efecto recesivo sobre la economía. En este sentido, es importante señalar siguiendo a este autor, que la experiencia histórica de Venezuela indica que cualquier deterioro en los precios del petróleo es suficiente para que la estadística de la pobreza vuelva a incrementarse.

En Maracaibo - capital del estado Zulia y segunda ciudad de Venezuela, ubicada en la costa occidental del Lago de Maracaibo (Gráficos 1 y 2) - más del $60 \%$ del territorio urbano está ocupado

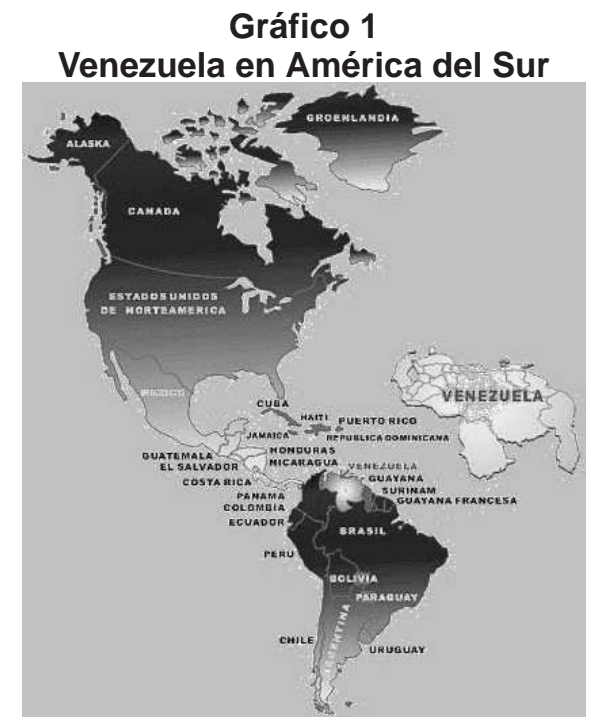

Fuente: González y Rincón 2005. por barrios producto de invasiones y viviendas precarias (urbanización de la pobreza), sin los servicios básicos que requiere un hábitat sostenible y sin las condiciones socioculturales que propicien una ciudadanía plena (González, 2003). Esta realidad justificó la creación -por iniciativa de un grupo de profesores de la Facultad de Arquitectura de la Universidad del Zulia- del Programa Ciudadanía Plena (PCP) en 1997. El PCP tiene como propósito fundamental de acuerdo a González la superación de la pobreza promoviendo el desarrollo local sostenible en sus tres niveles: social, ambiental y económico y, mediante la implementación de un nuevo Modelo de Gestión Urbana, a través de un consorcio que integra a los diferentes actores involucrados e interesados en la solución de esta problemática en Maracaibo.

EI PCP surge para actuar sobre el hábitat precario y la falta de reconoci-

\section{Gráfico 2 \\ Sur América. Venezuela y Maracaibo en el Estado Zulia}

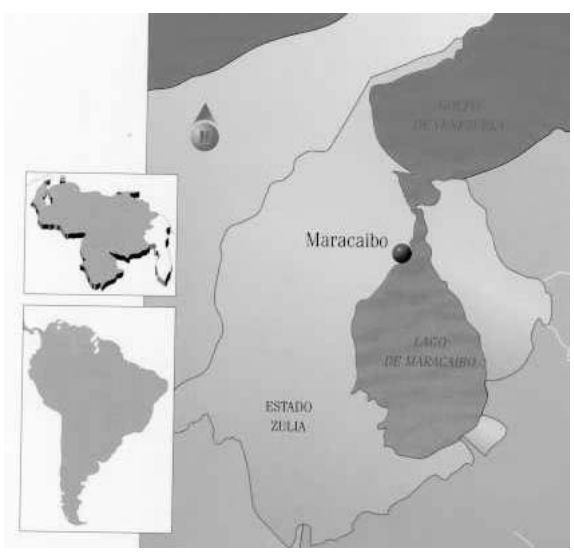

Fuente: González y Rincón 2005. 
Estrategia de evaluación innovadora

Ferrer, Mercedes; Gómez, Nersa y Reyes, Ramón

miento de valores ciudadanos según González (2003), y propone y gestiona la creación de nuevas y creativas oportunidades como microcréditos para la rehabilitación de viviendas y pequeños negocios, contribuyendo de esta manera al desarrollo urbano sostenible de los barrios de Maracaibo, desde la educación y capacitación de familias pobres. En este contexto, los microcréditos actúan como imán para atraer a personas y familias al programa, las cuales para acceder a ellos deben pasar por un proceso de capacitación que viabiliza su transformación cambio de cultura urbana - en ciudadanos plenos que, para González son aquellos que asumen con responsabilidad y plenitud (ética cívica) sus deberes y derechos ciudadanos.

Para diseñar la estrategia de evaluación del Modelo de Gestión del PCP y su potencial transformador en política urbana inteligente, objeto de este artículo se consideraron dos formas de entender la política (Montagut, 2000), por un lado, la definida como conjunto de medidas que afectan las estructuras de la sociedad e intentan modificar las contradicciones o problemas que en ellas se generan $y$, por el otro, las que interpretan el objeto de la política como conjunto de medidas que intentan resolver los conflictos generados, es decir, ayudan a la gobernabilidad. La investigación se ubica en este último enfoque, en el cual la política se expresa como una acción sobre unos medios para la consecución de fines, por lo tanto implica un cambio, una modificación, ya sea de situaciones, de sistemas o de prácticas de conducta. La política pública entendida como satisfacción de necesidades humanas, la práctica de demo- cracia deliberativa y dialogante y los niveles de participación, interacción y compromiso entre actores, son algunas de las categorías de análisis que se consideran en el diseño de la estrategia de evaluación del Modelo de Gestión del PCP.

El Modelo asume la democracia participativa y deliberativa como riqueza social, porque proporciona una categoría política que permite superar la simple demanda del cumplimiento de los derechos al ejercicio de una ciudadanía plena, mediante un nuevo pacto social o consorcio donde participan Hábitat LUZ (ONG de la Universidad del Zulia), el CESAP y la Alcaldía de Maracaibo, entre otros actores, promoviendo entre los ciudadanos la corresponsabilidad en la gestión, la coparticipación en la toma de decisiones políticas (política bottom up o de abajo arriba) y el cumplimiento de obligaciones ciudadanas. Para ello se concretaron espacios de diálogo que luego se transformen en acciones concretas desde la sociedad civil y el gobierno. De esta forma se fortalece la visión de lo público como espacio de corresponsabilidad, logrando así mayor articulación y compromiso entre los sectores sociales en la consecución de objetivos comunes (González, 2003).

Enmarcado en estas consideraciones en el artículo se presentan los primeros resultados de la investigación "Evaluación del Modelo de Gestión del Programa Ciudadanía Plena", financiada por Condes, referidos al diseño conceptual de la estrategia innovadora diseñada para evaluar y reconocer el potencial transformador del Programa Ciudadanía Plena (PCP) en una política urbana inteligente. 


\section{El Contexto: América Latina fin del siglo XX e inicio del XXI}

En América Latina las transformaciones estructurales de fines del siglo $X X$ representaron graves amenazas a la integración social, porque la ciudadanía, como realidad inacabada en la Región, se enfrentó a situaciones cada vez más restringidas por diferencias socioeconómicas crecientes (Spinelli, 2001). Esto obligó a reformular el ámbito de las prácticas sociales y abrió oportunidades para una reorganización social planteando condiciones favorables para que el eje de la política se desplazara del ámbito estatal al ciudadano. Se generó así un espacio para nuevas formas de democracia directa o participativa consustanciada con movimientos sociales que se ha expresado en diferentes formas de participación ciudadana, reproduciendo la solidaridad y fortaleciendo la articulación entre Estado y sociedad civil.

En la actualidad, la combinación de reforma del Estado y la globalización acentúa una nueva dinámica en los gobiernos locales con mayores competencias, con similares recursos y con una mayor evaluación por parte de la sociedad. En este sentido, Campbell (en Banco Mundial, 2005) especialista principal del Instituto del Banco Mundial sostiene que diversas olas de cambios fuertes tales como reformas políticas, descentralización, democratización y globalización, han arrojado a las ciudades dentro de un territorio desconocido en términos políticos y económicos. Para Campbell los gobiernos nacionales trasladan competencias a los gobiernos estatales y éstos a su vez a sus municipios en un marco de descentralización y mayor participación ciudadana como uno de los factores de la consolidación del sistema democrático. Esto constituye un desafío, pues obliga a reformular el ámbito de las prácticas sociales orientadas a la solución de los problemas ciudadanos y conceder atención a la institucionalización de las necesidades sociales y comunitarias, donde los individuos pueden participar en el desarrollo de prácticas adecuadas para atender sus necesidades. Por otro lado, las ciudades en respuesta a las presiones impuestas por la globalización están diseñando e implementando nuevas estrategias, formas de organización y gestión comunitaria.

Es importante destacar que para el año 2020 más de la mitad de los habitantes de los países en desarrollo vivirán en ciudades, las cuales se transforman en espacios claves para la lucha contra la pobreza en el siglo XXI. Esta realidad exige innovación en la conducción de lo público y una considerable audacia política. En América Latina, donde la pobreza y la desigualdad social en la distribución de la riqueza demuestran la gravedad de su situación, el fortalecimiento de la sociedad civil no puede favorecerse sólo con reformas jurídicas y políticas institucionales, de incluir la participación política entendida como la representación en condiciones de igualdad, de pluralismo político y de oportunidades de deliberación y en estas condiciones, los actores sociales se convierten en actores políticos (Campbell, 2005).

En este contexto, la formulación de la agenda política de cambios y el dialogo social, son elementos que contribuyen a la reducción de la pobreza y que se integran en el PCP mediante la asunción de los va- 
Estrategia de evaluación innovadora

Ferrer, Mercedes; Gómez, Nersa y Reyes, Ramón

lores del desarrollo sostenible (DS). El DS articula las dimensiones económicas, socio-cultural, políticas e impacta las decisiones de las políticas públicas con acciones orientadas a mejorar el acceso a financiamiento, mercados, nuevos esquemas de organización para formación de ciudadanía. En este sentido, el PCP utiliza la formación para generar capital social -asociaciones comunitarias- para velar por los valores de ciudadanía -corresponsabilidad en la gestión y solidarias, entre otros-. El desarrollo sostenible (DS) viabiliza la creación de oportunidades para los que no las tienen. En este sentido, el ser humano se constituye en el eje articulador de la economía, la sociedad y el Estado, viabilizando el ejercicio de la ciudadanía plena. El desarrollo sostenible asume que el Estado somos todos, dando lugar a la creación de una nueva cultura ciudadana que propende a la mejora de la calidad de vida, especialmente de los pobres (Cuadro 1).
Entre los factores que inciden en el desarrollo sostenible urbano (DSU), de acuerdo a Harris (en Ferrer et al, 2005), destaca la pobreza urbana que se expresa en la presencia de asentamientos ilegales, viviendas sin servicios básicos, el aumento de la morbilidad producto de la falta de infraestructura sanitaria, la congestión del tráfico, la proliferación de la violencia y el crimen y la expansión urbana a costa de tierras agrícolas, entre otros aspectos. El desarrollo sostenible reconoce la existencia de límites y conflictos, los primeros residen tanto en insuficiencias sociales, económicas, políticas y tecnológicas como en las propias del sistema natural y, los segundos, son inherentes a toda dinámica de cambio. Los primeros pueden ser superados gracias a la inventiva y capacidad humana, los segundos pueden ser gestionados en forma racional y, de esta forma, el DSU supera la dicotomía medio ambiente y desarrollo.

Para Reingeniería (2004) esta realidad abre un campo de propuestas nuevas y diferentes que incluye el fortaleci-

\section{Cuadro 1}

Componentes del Desarrollo Sostenible

\begin{tabular}{|c|c|c|}
\hline $\begin{array}{c}\text { Incremento de la } \\
\text { productividad (económico) }\end{array}$ & $\begin{array}{l}\text { Equidad social } \\
\text { (social) }\end{array}$ & $\begin{array}{l}\text { Protección ambiental } \\
\text { (ecológico) }\end{array}$ \\
\hline $\begin{array}{l}\text { Crecimiento macroeconómico } \\
\text { (PIB/IPC) + Potencial económi- } \\
\text { co de la ciudad o asentamiento } \\
\text { humano. } \\
\text { - RH disponibles y sus niveles de } \\
\text { educación y salud. } \\
\text { - Capacidad de inversión + in- } \\
\text { fraestructuras disponibles y su } \\
\text { vida útil. } \\
\text { - Arquitectura urbana de la ciudad } \\
\text { y la organización espacial de las } \\
\text { actividades. }\end{array}$ & $\begin{array}{l}\text { Grado de accesibilidad: } \\
\text { - Al trabajo. } \\
\text { - A los servicios públicos. } \\
\text { - A la toma de decisión. } \\
\text { - A la participación en el ingre- } \\
\text { so fiscal. } \\
\text { - A la salud, educación, movi- } \\
\text { lidad y vivienda, entre otros. }\end{array}$ & $\begin{array}{l}\text { Del medio natural (MN) y el } \\
\text { medio construido (MC): } \\
\text { MN: Incluye la conservación, } \\
\text { la rehabilitación, el control de } \\
\text { la explotación de recursos y } \\
\text { los planes de manejo, entre } \\
\text { otros. } \\
\text { MC: El sistema de espacios } \\
\text { públicos, el patrimonio y la } \\
\text { estructura urbana (Hardoy en } \\
\text { Cárdenas, 2004). }\end{array}$ \\
\hline
\end{tabular}

Fuente: Ferrer et al (2005). Nota: $\mathrm{RH}=$ Recursos Humanos. MN= Medio Natural. MC = Medio Construido. 
miento de mecanismos participativos en la toma de decisiones o policy making (políticas de abajo arriba); la conceptualización del gobierno local como facilitador de procesos de habilitación ambiental; la concreción de instancias de trabajo público-privado, la planificación de carácter indicativo; espacios de negociación para los proyectos, la coordinación como elemento central y el fomento de los procesos de participación en la gestión urbana y el manejo de información para la toma de decisiones. Características que conforman una política urbana inteligente.

\section{Política Urbana Inteligente, Ciudadanía Plena, Modelo de Gestión Urbana y Evaluación Estratégica de Políticas}

La efectividad del PCP, del Modelo de Gestión implantado y su potencial de mutación o cambio en política urbana inteligente, es lo que determina el alcance de la investigación, por ello debe ser revi- sado a través de una estrategia de evaluación que permita el manejo de diferentes elementos conceptuales para entender la pobreza y sostenibilidad del hábitat, el nivel de compromiso y participación de los actores involucrados en la toma de decisiones, así como lo concerniente al cumplimiento de acuerdos y objetivos que fortalece la apropiación del PCP y su permanencia en la agenda publica local.

\subsection{Políticas Publicas y Política Urbana Inteligente}

Brugué y Gomà y Gomà y Subirats (1998:28 y 1999:389) y Subirats (1989) sostienen que, gran parte de los análisis empíricos de las políticas públicas siguen el modelo de fases o procesos, en el cual las políticas públicas recorren un itinerario no estrictamente lineal, con interacciones complejas entre fases pero de lógica secuencial. El recorrido, según estos autores es fragmentable en tres grandes fases (Cuadro 2).

Cuadro 2

Dimensiones Analíticas y Fases de Elaboración de Políticas

\begin{tabular}{|c|c|c|c|c|}
\hline \multirow{3}{*}{$\begin{array}{l}\text { Dimensiones } \\
\text { Analíticas }\end{array}$} & \multicolumn{4}{|c|}{ Fases de elaboración de políticas } \\
\hline & \multirow{2}{*}{\begin{tabular}{|c|} 
FASE 1 \\
Construcción de \\
Problemas y \\
Agendas
\end{tabular}} & \multicolumn{2}{|c|}{ FASE 2} & \multirow{2}{*}{$\begin{array}{c}\text { FASE } 3 \\
\begin{array}{c}\text { Proceso de } \\
\text { Implementación }\end{array}\end{array}$} \\
\hline & & $\begin{array}{l}\text { Proceso de } \\
\text { Negociación }\end{array}$ & $\begin{array}{c}\text { Toma de } \\
\text { Decisiones }\end{array}$ & \\
\hline Simbólica & $\begin{array}{c}\text { Conflictos } \\
\text { Epistemológicos }\end{array}$ & & & \\
\hline De Estilo & & $\begin{array}{l}\text { Modelos de } \\
\text { Interacción }\end{array}$ & & \\
\hline Sustantiva & & & $\begin{array}{c}\text { Opciones de } \\
\text { Fondo }\end{array}$ & \\
\hline Operativa & & & & $\begin{array}{l}\text { Escenarios de } \\
\text { Gestión }\end{array}$ \\
\hline
\end{tabular}


Estrategia de evaluación innovadora

Ferrer, Mercedes; Gómez, Nersa y Reyes, Ramón

En la primera fase, se desarrolla el proceso de identificación de los problemas y el acceso de algunos temas a la agenda pública de actuación, en la segunda, se desarrolla el proceso de negociación entre alternativas de actuación que conduce a la formación de mayorías y a la toma de decisión y en la tercera fase, se establecen los escenarios organizativos y de gestión (el Modelo de Gestión del PCP se ubica en esta Fase), que posibilitan la ejecución de las decisiones tomadas.

Para Brugué y Gomà (1998:28) y Gomà y Subirats (1999:389), el modelo descrito anteriormente permite ubicar sobre cada una de las tres fases de elaboración de políticas públicas las cuatro dimensiones de toda intervención pública: la Dimensión Simbólica, que se relaciona con la construcción de estrategias discursivas y marcos cognitivos, que adquiere mayor relieve en el conflicto epistémico, sobre la definición del problema e inclusión en la agenda; la Dimensión de Estilo, que observa las actitudes, disposiciones y estrategias de los actores y cristaliza en la fase de negociación. La Dimensión Sustantiva, tiene que ver con los contenidos, con las grandes opciones de fondo y tiende a concretarse con más fuerza en el proceso de toma de decisión y, la Dimensión Operativa, que considera modos y valores de gestión y se ubica en la fase de implementación.

De acuerdo a Subirats (Ferrer, 2003), para analizar la formación de las políticas públicas es necesario considerar cinco aspectos contextuales clave: La democracia como régimen político; La ruptura de la unidad del sistema reconociendo las diferentes racionalidades de los sujetos que participan en la acción pública y los recursos de que disponen; La legitimidad de la acción de los poderes públicos basada más en la capacidad de respuesta a las demandas de los actores implicados en sus ámbitos de actuación, que en su teórica legitimidad ideológica o constitucional; El centro de la atención se ha desplazado de la legitimidad formal, a la capacidad de dar respuesta a las demandas de todos los sectores y esferas de la sociedad (creciente pragmatismo), donde la capacidad de gestión es la clave de la acción pública y, la difuminación creciente entre lo público y lo privado y la pérdida de valor del concepto de servicio público (no basta con asegurar la legalidad formal del proceso).

En relación con la formación de las políticas públicas Subirats, plantea cinco preguntas para definir los instrumentos y las técnicas para abordar su estudio:

- ¿Por qué se ha escogido el problema como prioritario?

- ¿Cuáles son los objetivos que se persiguen?

- ¿Cuál es el camino para su puesta en práctica y su efectividad?

- ¿Cuáles son los resultados de esa acción administrativa?

- ¿Valió la pena el esfuerzo desarrollado?

Para este autor, este enfoque permite una descripción más real de la realidad político administrativa, facilita el seguimiento de los procesos de elaboración y desarrollo de los programas de actuación pública y el entramado de actores que intentan influir en los mismos. Subirats (1989), identifica cuatro etapas en el proceso de análisis de la política pública, 
que coincide con el proceso planteado con Brugué y Gomà (1998): 1‥ Definición del problema, inicia la puesta en marcha de la política pública y debe estar vinculada a las soluciones que genera y al proceso que transforma una situación problema en tema de relevancia pública para su inclusión en la agenda pública o, programa general de actuación de los poderes públicos y debe ser analizado desde una perspectiva de soporte a los decisores públicos. $2^{\circ}$. Estudio de alternativas de acción, fijación de objetivos y toma de decisión. En esta etapa prospectiva se prevén las posibles consecuencias de cada alternativa y se analiza el proceso de toma de decisión desde una perspectiva no sólo descriptiva sino también prescriptiva. $3^{\circ}$. Puesta en práctica e, implementación de las políticas (programas -PCP-, proyectos y/o acciones) para dar solución a los problemas y, 4ํㅜ․ Análisis de resultados, comparación de resultados versus objetivos. El proceso de evaluación de la política, incluye la selección del tipo de evaluación y los protagonistas, que es el objeto de esta investigación (Cuadro 3).
En este contexto es importante definir qué es una política urbana inteligente, ya que el potencial transformador del PCP se evalúa y reconoce estratégicamente a través de los aspectos que caracterizan esta tipología. Una política urbana inteligente -PUI- es para Ferrer, una política bottom up o de abajo arriba, que involucra a los ciudadanos pluralidad de actores de base, en su formulación y gestión, legitima al alcalde por desempeño porque da respuesta a las demandas ciudadanas y en consecuencia genera gobernabilidad, cohesión-capital social y emponderamiento ciudadano, "ciudadanía plena" fundada en valores éticos. La política urbana inteligente promueve la formación de compromiso público-privado y comunitario, consorcios o paternariados, fortaleciendo el potencial para resolver problemas y el logro de la visión compartida de ciudad en un contexto de liderazgo compartido. Es una nueva praxis política que genera rentabilidad social porque soluciona problemas concertadamente y promueve una nueva cultura política, urbana y ciudadana.

\begin{tabular}{|c|c|c|c|}
\hline \multicolumn{4}{|c|}{$\begin{array}{c}\text { Cuadro } 3 \\
\text { Análisis de Políticas Públicas }\end{array}$} \\
\hline \multicolumn{4}{|c|}{ ETAPAS } \\
\hline ETAPA 1 & ETAPA 2 & ETAPA 3 & ETAPA 4 \\
\hline $\begin{array}{c}\text { Definición } \\
\text { del Problema }\end{array}$ & $\begin{array}{l}\text { Estudio de } \\
\text { alternativas de acción }\end{array}$ & $\begin{array}{c}\text { Proceso de } \\
\text { Implementación }\end{array}$ & Evaluación \\
\hline
\end{tabular}

Proceso de transfor- Fijación de objetivos, Implementación de Análisis de resultamación de una situa- toma de decisión y análi- las políticas para dar dos, comparación reción problema en sis de las consecuencias solución a los proble- sultados versus objetitema de relevancia de cada alternativa. mas vos pública y su inclusión en la agenda pública.

Fuente: Elaboración propia a partir de Subirats (1989). 
Estrategia de evaluación innovadora

Ferrer, Mercedes; Gómez, Nersa y Reyes, Ramón

La visión propuesta del PCP conlleva su asunción como esfuerzo colectivo y negociado entre las diferentes instituciones, estructuras políticas de la ciudad y las comunidades participantes. En este contexto, se puede señalar que el PCP responde a un problema identificado por diferentes actores como prioritario, la pobreza urbana, tiene claramente establecidos sus objetivos y el camino o ruta para su puesta en práctica mediante un Modelo de Gestión consorciado y participativo, que se evalúa con el fin de identificar su potencial para mutarse en PUI y establecer los correctivos necesarios que permitan mejorar su impacto en la superación de la pobreza y en consecuencia, su permanencia en la agenda de los actores involucrados.

\subsection{Ciudadanía plena, derechos ciudadanos y participación}

Para Borja (2004) la ciudad no es sólo el espacio sino el conjunto de personas y, en este sentido, los nuevos desafíos exigen la defensa y la extensión de los derechos ciudadanos orientados y apoyados por instituciones y movimientos cívicos. Este reto implica una participación ciudadana y una respuesta política que tenga en cuenta las necesidades de toda la ciudadanía teniendo presente los derechos conferidos legalmente. El desarrollo y legitimación de estos derechos dependerá para este autor, de un proceso cultural y de la hegemonía de los valores que están en la base de estos derechos - un proceso social y de movilización ciudadana para conseguir su legalización, la creación de mecanismos y pro- cedimientos que los hagan efectivos y, un proceso político-institucional para formalizarlos, consolidarlos y desarrollar las políticas para hacerlos efectivos. Los nuevos derechos de ciudadanía de acuerdo a Borja (2004), contemplan el derecho a ejercer el conjunto de libertades urbanas en cuanto al lugar, al espacio público, a la identidad colectiva dentro de la ciudad, a la movilidad y la accesibilidad, así como:

- Derecho a la protección por parte del gobierno, el gobierno local debe actuar de defensor de oficio y gestor de los ciudadanos. La actuación concertada entre la institución local y la sociedad civil organizada es hoy una demanda inaplazable de las mayorías ciudadanas en la medida que puede asegurar el establecimiento de las políticas y la coparticipación y compromiso mutuo en la solución más eficaz de los problemas de la ciudadanía.

- Derecho a la innovación política: Los gobiernos locales y regionales deben recoger las demandas sociales para innovar en cuanto a mecanismos de participación, instrumentos de planeamiento y de gestión, entre otros.

- Derecho y responsabilidad como ciudadano: en este sentido, se confiere a todos los residentes en una ciudad igualdad en cuanto al status políticojurídico. La ciudadanía debe distinguirse de la nacionalidad, se trata de la relación con un territorio y con un entorno social, lo que debe determinar el marco legal y operativo de las instituciones.

- Derecho a que los representantes directos de los ciudadanos tanto institu- 
cionales (gobierno local y/o regional) como sociales (organizaciones profesionales, económicas, sindicales, territoriales, entre otros) participen o accedan a los organismos que tratan cuestiones que los afectan directamente.

- Derecho de los ciudadanos a igual movilidad y acceso a la información que poseen las instituciones públicas, acceder a todo tipo de información emanada de los organismos públicos y a la movilidad en los espacios políticos y económicos en los que se encuentran inmersos.

- Derecho de los gobiernos locales, regionales y de las organizaciones y ciudades a constituir redes y asociaciones que actúen y sean reconocidas a escala local, nacional e internacional. El seguimiento y regulación debe ser realizada por las instituciones locales en conjunto con las organizaciones comunales afectadas.

- Derecho a desarrollar una identidad colectiva como comunidad de ámbito local-urbano y a conquistar la cota de autogobierno que ésta misma comunidad determine libremente, sin excluir a ningún habitante de sus derechos ciudadanos.

En la medida que en muchos casos estos derechos aparecen como una novedad política y no tienen aún el suficiente arraigo social, el rol de las instituciones es hoy fundamental, como fuerza político-social y como organismos capaces de definir los contenidos y las motivaciones de estos derechos. Las formas de ciudadanía democrática exigen la participación efectiva de la mayoría de la población y requiere el acceso de todos a los recursos de la sociedad y modalidades de organización y participación política que estén enraizadas en las condiciones culturales propias de esa sociedad (Cunill Grau, 1997). La participación ciudadana apunta hacia una transformación en el desarrollo de una institucionalidad de representación social capaz de controlar y participar a nivel del gobierno municipal, así como de búsqueda de espacios sociales en los cuales los individuos logren producir actividades que expresen su necesidad. Esta participación se manifiesta en prácticas de pluralización del debate público, desarrollado por organizaciones autónomas e informales.

Los escenarios de participación en espacios institucionales y políticas públicas, las expectativas sociales se basan en el seguimiento de los procesos que pudieran estar construyendo una nueva relación entre gobierno y sociedad civil organizada. Las tendencias actuales y las políticas de participación llevan al aumento de oportunidades, donde las particularidades son de suma importancia para desarrollar una capacidad estratégica local. Para ello cada municipio dispone de un conjunto de recursos humanos, naturales y financieros, un potencial histórico, cultural e infraestructural, un saber tecnológico que constituye su potencial de desarrollo y la integración desde los actores puede potenciar una identidad y autonomía a partir de una nueva concepción de ciudadanía, que patentiza la importancia de políticas de consenso y la configuración de nuevos espacios de solidaridad basadas en lo económico y social. 
Estrategia de evaluación innovadora

Ferrer, Mercedes; Gómez, Nersa y Reyes, Ramón

\subsection{Modelos de Gestión Pública Urbana y Estrategias Creativas de Gestión}

En América Latina, se distinguen tres modelos básicos de gestión de la administración publica de acuerdo a Spinelli (2001): Populista, que busca atender necesidades populares construyendo relaciones clientelares que permiten acumular poder político de conducción centralizada que impide la autonomía, el apoyo a la diversidad de iniciativas sociales y establece un estricto control político de los actores sociales. Tecnocrático, que persigue la eficiencia, la eficacia y la productividad a partir de una visión pragmática, el uso de recursos tecnológicos y la imposición de controles autoritarios que permiten imponer sus planteamientos y, el Participativo, que abre espacios orientados a la construcción de una gestión pública participativa y corresponsable entre gobierno y sociedad civil, fomentando la organización social autónoma y la cogestión, la interacción multiactoral y la operación de instrumentos que faciliten la concertación y la participación social en las decisiones, en la definición de políticas públicas, en la conducción de los programas y en el control social del desempeño público.

De estos tres modelos el rentista-populista-clientelar es el que caracteriza la práctica política en Venezuela por las razones antes señaladas y porque construye relaciones que le permiten acumular poder político centralizado, potenciar la dependencia y controlar a los ciudadanos, lo cual inviabiliza la construcción de ciudadanos libres y plenos. En este sentido, España (2006: 55) afirma que la reducción de la pobreza en Ve- nezuela actualmente se debe mayoritariamente a las becas educativas de las misiones (según lo declara el gobierno) por lo que estamos en presencia de un subsidio que no tiene contraprestación productiva, por lo que solo se están atacando las consecuencias de la pobreza. Esta praxis fortalece la dependencia clientelar.

Por otro lado, la gestión pública urbana según Herzer y Pírez (1993) es generadora de políticas que se concretan en programas y en la ejecución de proyectos dentro de la organización, de acuerdo a circunstancias locales y coyunturales. Este proceso conlleva la descentralización de competencias, el aumento de demandas y de la evaluación por parte de las sociedades civiles locales, lo que implica la modificación del modelo de gestión tradicional de los municipios y su forma de relación con la sociedad local. En estos escenarios, el municipio interviene más directamente en el tema social haciéndose cargo de los conflictos locales, en una situación cada vez más compleja, con una pobreza más heterogénea y el reclamo constante de la población por el ejercicio de su ciudadanía y de los derechos adquiridos.

La Nueva Gestión Pública (NGP) del municipio promueve la concertación y articulación de las relaciones públicasprivadas y sociedad civil. En este contexto se inscribe el modelo de gestión local del PCP, que surge de iniciativas de la sociedad civil y que la alcaldía de Maracaibo apoya para satisfacer demandas sociales básicas. Esta NGP ha generado la necesidad de construir capacidades técnicas, organizativas y de gestión en los gobiernos municipales para dar respuesta a las 
demandas de la población más afectada por estas transformaciones. En este sentido, la nueva gestión local esta comenzando a incorporar mecanismos de evaluación de las políticas e instrumentar mecanismos de seguimiento y monitoreo de las mismas considerando la opinión de los actores involucrados.

La capacidad de gestión social de los gobiernos locales está vinculada directamente con la posibilidad de dar respuesta a las expectativas y necesidades de la población local y la capacidad de co-responsabilizar a la propia sociedad, tanto en el control como en la participación e implementación de las políticas sociales (Consejos Comunales cuya Ley se ha aprobado recientemente). En este sentido, el PCP ha establecido redes de conexión con nuevas formas de organización social -ONG, entidades intermedias, organizaciones de base, iglesia, entre otras- que interactúan en la gestión pública tanto en el control como en la aplicación de algunas políticas. De acuerdo a Arroyo (1997), el impacto esperado de las políticas sociales en el gobierno municipal y la aplicación de programas y políticas sociales se concreta en la articulación entre los planos técnicos, políticos y sociales, la capacidad técnica o nivel de profesionalización de la administración, los estilos de gestión política y los niveles de participación de las organizaciones de la sociedad civil. Este es el desafío de los gobiernos municipales y del PCP, tratar de articular sus acciones con esa parte de la sociedad organizada y no organizada fortaleciendo sus vínculos a fin de ampliar el modelo de gestión municipal a algo más que sólo el equipo de gobierno de turno (Arroyo, 1997).
Los procesos de gestión, además de factores socioeconómicos dinámicos, disponibilidad de recursos tangibles e intangibles, financiamiento, según Johannisson et al. (1993), requieren de estrategias creativas que sean propicias para que la incorporación ciudadana a la gestión pública madure y prospere en un ambiente de colaboración entre sus actores. Se trata de ofrecer una alternativa integral que incluya los distintos ámbitos de desarrollo de la sociedad y de los individuos a favor de la promoción de nuevas formas de gestión y alianzas en la toma de decisiones públicas y construcción de un contexto favorable para la gestión urbana donde predomine la «preocupación general» para el "co-funcionamiento". Este ambiente favorable, surgirá en una comunidad con alto nivel de capital social, confianza entre los actores y normas de comportamiento apropiadas, ello implica que, confianza, interacción y coparticipación, son prerrequisitos necesarios para el desarrollo económico local y la construcción de ciudadanía. La estrategia apropiada es promover el desarrollo del capital social fortaleciendo las capacidades de las instituciones locales para que puedan generarse acciones hacia las comunidades y propiciar las vinculaciones, alianzas transversales, cogestión y autogestión en escenarios de transformación social, política y económica.

Por otro lado, la gestión urbana sostenible según Ferrer et al. (2000), es el conjunto de acciones/procedimientos para lograr el desarrollo de la ciudad, considerando los componentes económicos, ambientales y sociales del desarrollo sustentable. Franchini y Dal Cin (2000: 42) coinciden con este planteamiento cuando 
Estrategia de evaluación innovadora

Ferrer, Mercedes; Gómez, Nersa y Reyes, Ramón

asumen la sostenibilidad como "el estado deseado o, patrón de calidad de vida logrado a través de un proceso de desarrollo sostenible que llevaría a alcanzar los tres principios que alientan el nuevo modelo, bienestar social, eficiencia económica y sostenibilidad ecológica". Por otro lado, según Ramos (2002) el Consejo Internacional de Iniciativas locales (ICLEI) asume el desarrollo sustentable de la gestión urbana como "un desarrollo que distribuye servicios ambientales, económicos y sociales básicos a todos, sin alterar la viabilidad de los sistemas ecológicos y comunitarios de los que esos servicios dependen" (Cuadro 4).

\section{Modelo de Gestión del PCP}

Para el PCP una ciudadanía plena y un contexto urbano sostenible viabiliza la reducción de la pobreza urbana (tesis básica). El mecanismo utilizado para lograr estos objetivos es la formación individual y colectiva en valores -responsabilidad, soli- daridad, participación en la toma de decisión y cogestión, entre otros - fundamentales para fortalecer el capital social.

\subsection{Antecedentes: El Programa de Gestión para América Latina y el Caribe (PGU-ALC /UN - HÁBITAT)}

EI PGU-ALC /UN-HABITAT es el resultado del Programa de Cooperación de las Naciones Unidas para el Desarrollo (UNDP) cuyo propósito es fortalecer la capacidad de gestión urbana hacia el desarrollo sostenible en ciudades de Latinoamérica y del Caribe, a partir de la vinculación de las instituciones regionales y locales de más de 40 ciudades de la región para compartir y capitalizar experiencias. Las diferentes ciudades participan a través de las asociaciones de vecinos, los cuales asumen las funciones de promover y generar espacios de relación entre los distintos agentes urbanos, compartiendo paradigmas que son la base de su actuación (González, 2003).

\section{Componentes y Dimensiones de la Gestión Sostenible}

\begin{tabular}{|c|c|}
\hline $\begin{array}{l}\text { Componente/ } \\
\text { Dimensión }\end{array}$ & Aspectos Involucrados \\
\hline 1. Componente social & Bienestar entendido como: salud, educación, vivienda y empleo. \\
\hline 2. Dimensión política & $\begin{array}{l}\text { Gobiernos locales autónomos + derechos humanos + libertad políti- } \\
\text { ca de decisión. }\end{array}$ \\
\hline 3. Aporte económico & $\begin{array}{l}\text { Generación de riquezas + mejores condiciones de vida = cambio en } \\
\text { los actuales patrones de consumo + distribución equitativa. }\end{array}$ \\
\hline 4. Dimensión cultural & $\begin{array}{l}\text { Rescata la identidad de los lugares y de los pueblos, para asumir al- } \\
\text { ternativas propias. }\end{array}$ \\
\hline 5. Componente ético & Proponen un desarrollo con equidad, donde todos ganan. \\
\hline 6. Componente ecológico & $\begin{array}{l}\text { Asume la conservación de la naturaleza como proveedora de recur- } \\
\text { sos + servicios. }\end{array}$ \\
\hline
\end{tabular}

Fuente: Ferrer et al a partir de Ramos (2004). 
4.2. El Programa Ciudadanía Plena: Una alianza estratégica entre actores nacionales e internacionales

EI PCP se inicia con la firma de una carta de intención en Florencia (Italia) en 1997 entre la Alcaldía de Maracaibo, el Programa de Gestión Urbana para América Latina y el Caribe (PGU-ALC) adscrito al PNUD y la Universidad del Zulia (LUZ), con el objetivo de enfrentar de forma decidida la pobreza urbana en la ciudad de Maracaibo (Venezuela). Los actores intervinientes, la razón social y los principios rectores del PCP se presentan en el Cuadro 5.

En el marco del Convenio firmado en el 2002, según González (2003), la Fundación Hábitat LUZ, ONG de la Universidad del Zulia asumió la responsabilidad de coordinar el sub-proyecto Mejora del Hábitat y la Vivienda. Este proyecto abarca tres áreas: diagnostico, asistencia técnica y capacitación. El subprograma de Capacitación Técnica se inicio en Mayo de 2004 y cubrió diez ciclos de cuatro talleres cada uno referidos a: Calidad de vida y ambiental, Vivienda progresiva y lectura de planos, Producción de la vivienda progresiva e Inspección de obras.

Este programa es medular en el proceso para lograr el cambio cultural y formar ciudadanos plenos.

En el Gráfico 3 se muestran las comunidades atendidas en Maracaibo en los años 2003 y 2005 y se aprecia el aumento de la cobertura territorial del PCP.

En el Cuadro 6 se describen los paradigmas y principios rectores que comparten los agentes participantes en el PCP.

La consecución de los objetivos del PCP se apoya en las estrategias siguien- tes: La motivación, capacitación y formación comunitaria en diversas áreas del individuo, la familia y la comunidad. La generación de espacios de participación, dialogo y negociación con las instancias gubernamentales, relacionadas con las decisiones de la realidad urbana de Maracaibo y, los incentivos como microcréditos, involucran al ciudadano no como el fin del crédito, sino como un sujeto que garantiza el mismo, mediante el respaldo del ahorro familiar. En el Cuadro 7, se presentan los objetivos del PCP.

En relación con esta última estrategia se crea en el 2001, EI Fondo Rotatorio de Crédito, Servicio Autónomo Mircrofinanciero de Maracaibo (SAMI), con personalidad jurídica propia adscrito a la Alcaldía de Maracaibo. EI SAMI inicia el otorgamiento de microcréditos en 2003 (Cuadro 8), obtenidos del Fondo Intergubernamental para la Descentralización (FIDES).

EI SAMI funciona con aportes de fondos de los diferentes socios del PCP y del Fondo Intergubernamental para la Descentralización - FIDES -. La estructura organizativa del SAMI está legalmente conformado por un presidente, nombrado por el Alcalde y por una Junta Directiva en la cual hay representación de las diferentes organizaciones involucradas en el PCP.

Las familias para acceder al crédito deben demostrar un ahorro equivalente del $20 \%$ del monto del crédito en una cuenta bancaria abierta bajo las condiciones establecidas por el fondo rotatorio. El interés sobre saldo deudor es del $30 \%$ anual, lo que equivale a un interés anual del $16 \%$, significativamente menor que las otras fuentes de financiamiento a las que las familiar pudieran acceder, entre ellas prestamistas informales. Se crean 
Estrategia de evaluación innovadora

Ferrer, Mercedes; Gómez, Nersa y Reyes, Ramón

\section{Cuadro 5}

Actores Involucrados en Alianza Estratégica PCP

\begin{tabular}{|c|c|c|}
\hline ACTORES & RAZÓN SOCIAL & Principios RECTORES \\
\hline Alcaldía de Maracaibo & $\begin{array}{l}\text { Corporación coordinada por el } \\
\text { Alcalde elegido por voto directo } \\
\text { popular. Poder autónomo que } \\
\text { consta de un cuerpo ejecutivo la } \\
\text { Alcaldía y otro legislativo, la Cá- } \\
\text { mara Municipal. }\end{array}$ & \multirow{3}{*}{$\begin{array}{l}\text { 1.- Gobernabilidad democráti- } \\
\text { ca. } \\
\text { 2.- Participación efectiva de la } \\
\text { pluralidad de actores involucra- } \\
\text { dos e interesados. } \\
\text { 3.- Gestión Sustentable } \\
\text { 4.- Respeto a la legalidad urba- } \\
\text { na: Planes Urbanos apoyados } \\
\text { en el proceso de construcción } \\
\text { de ciudadanía plena. }\end{array}$} \\
\hline $\begin{array}{c}\text { Nuevo Amanecer } \\
\text { CESAP }\end{array}$ & $\begin{array}{l}\text { Asociación de de } 27 \text { organiza- } \\
\text { ciones de carácter privado con } \\
\text { interés publico. Asesora la con- } \\
\text { secución de microcréditos, ca- } \\
\text { pacita y forma a comunidades } \\
\text { pobres desde } 1974 \text { (CESAP, } \\
2002 \text { ). }\end{array}$ & \\
\hline $\begin{array}{l}\text { Fundación Hábitat - LUZ } \\
\text { (ONG) }\end{array}$ & $\begin{array}{l}\text { ONG de LUZ que capacita y for- } \\
\text { ma a comunidades y da asisten- } \\
\text { cia técnica integral vinculada a } \\
\text { la construcción de vivienda y } \\
\text { proyectos urbanos. Área de ac- } \\
\text { tuación estados Zulia y Falcón. }\end{array}$ & \\
\hline \multirow[t]{2}{*}{$\begin{array}{c}\text { IFAD-LUZ } \\
\text { Instituto de Investigación } \\
\text { Facultad de Arquitectura } \\
\text { LUZ }\end{array}$} & $\begin{array}{l}\text { Institución académica con larga } \\
\text { experiencia en la realización de } \\
\text { planes, proyectos urbanos y co- } \\
\text { munitarios. }\end{array}$ & \\
\hline & $\begin{array}{l}\text { Programa de las NU* para los } \\
\text { asentamientos Humanos y re- } \\
\text { sulta de la cooperación del } \\
\text { PNUD con diferentes agencias } \\
\text { bilaterales. El objeto del PGU es } \\
\text { fortalecer la capacidad de ges- } \\
\text { tión urbana hacia el desarrollo } \\
\text { humano sostenible (PGU-ALC, } \\
\text { 2003) }\end{array}$ & \\
\hline Comunidades Locales & $\begin{array}{l}\text { Asociaciones de vecinos res- } \\
\text { ponsable de las relaciones inte- } \\
\text { ractorales en su territorio. }\end{array}$ & \\
\hline CECOSEZUL ** & $\begin{array}{l}\text { Central de Cooperativas del es- } \\
\text { tado Zulia, se incorpora para in- } \\
\text { cluir este modelo en el PCP. }\end{array}$ & \\
\hline
\end{tabular}

Fuente: Elaboración propia a partir de González (2003: 29-30). *NU: Naciones Unidas y PNUD: Programa de Naciones Unidas para el Desarrollo. ${ }^{*}$ CECOSEZUL se incorporará al PCP próximamente. 


\section{Gráfico 3}

PCP Comunidades atendidas

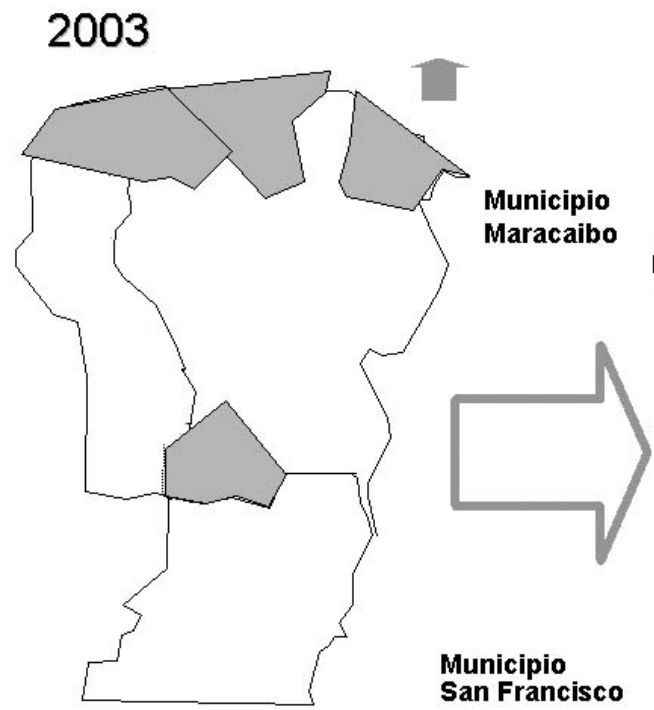

2005

12 comunidades

4 parroquias

San Francisco

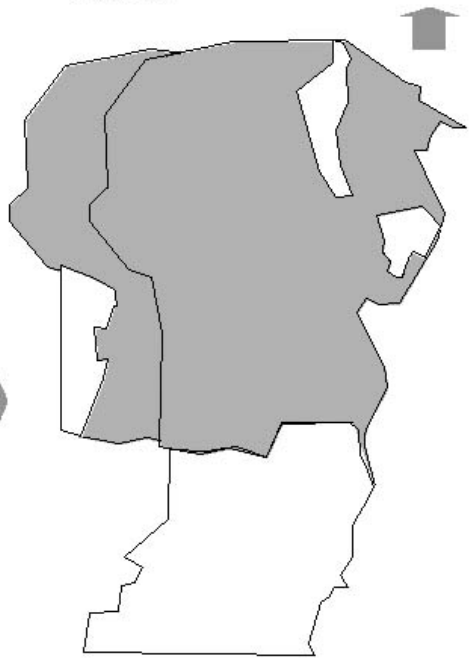

59 comunidades

15 parroquias

Fuente González y Rincón, 2005.

\section{Cuadro 6}

Paradigmas compartidos por agentes del PCP

\begin{tabular}{ll}
\hline Paradigma & \multicolumn{1}{c}{ Principios Rectores } \\
\hline Gobernabilidad & - Autonomía Local apoyada en procesos de descentrali- \\
& zación regional y local. \\
& Participación y concertación de todos los actores de la \\
& sociedad local (comunidad, ONG's, academia y gobier- \\
& no). \\
Participación efectiva de los & toma de decisiones en ambiente equitativo y justo. \\
actores locales & La comunidad agente, independiente, responsable y \\
& autónoma. \\
Planificación e implementación & - Autosostenibilidad económica, social y ambiental como \\
de Proyectos y Acciones & meta. \\
Conciencia Urbano-ambiental & intervención adecuada al ambiente natural y urbano. \\
& Proyecto como empresas acorde con los planes y obje- \\
& tivos locales.
\end{tabular}


Estrategia de evaluación innovadora

Ferrer, Mercedes; Gómez, Nersa y Reyes, Ramón

\section{Cuadro 7 \\ Objetivos General y Específicos Del PCP}

\begin{tabular}{l} 
Objetivo General \\
\hline Fortalecer el ejercicio de los deberes y dere- \\
chos que implican una ciudadanía plena, para \\
desarrollar e institucionalizar un modelo demo- \\
crático de gobierno, apoyado en la participa- \\
ción y consulta ciudadana e institucional, en \\
pro de resolver los problemas sociales y físicos \\
de diversas naturaleza y complejidad en la ciu- \\
dad de Maracaibo, Venezuela.
\end{tabular}

dad de Maracaibo, Venezuela.
Fortalecer todas las dimensiones del individuo, la familia y la comunidad, así como la organización y la participación comunitaria

Mejorar las condiciones cualitativas y cuantitativas de las viviendas de las familias de zonas de altos índices de pobreza; y, contribuir al ordenamiento urbano de Maracaibo con criterios de sostenibilidad.

Fortalecer la economía local, incentivando y afianzando iniciativas microempresariales creativas, renovadoras y/o autogestionarias hasta ahora desatendidas; generando oportunidades de trabajo.

Generar condiciones sociales y físicas que favorezcan la organización/participación social activa y la búsqueda de soluciones a las necesidades de las comunidades y la descentralización de funciones municipales.

Fuente: elaboración propia a partir de González (2003).

los "grupos solidarios" como estructura organizativa que propicia la recuperación de los créditos, al funcionar estos como una comunidad de co-deudores con responsabilidades legales, integrada por entre tres y cinco beneficiarios. Los grupos solidarios han permitido recuperar un $90 \%$ de los créditos, demostrando la eficacia de la agrupación mancomunada.

De acuerdo a González (2003), el crédito es liquidado en su mayoría directamente en materiales constructivos y equipos que son pagados a los proveedores, otorgándose únicamente en efectivo lo correspondiente a partidas de mano de obra. Los proveedores son seleccionados de forma libre y pública por medio de procesos de licitaciones. El programa en su etapa actual se aplica en cuatro parro- quias del Municipio Maracaibo: Coquivacoa, Idelfonso Vásquez, Antonio Borjas Romero y Luís Hurtado Higuera, ubicadas todas en la periferia de la ciudad, la cobertura del PCP, a estas parroquias incluye tanto el acceso al fondo rotatorio, como las actividades de formación, de capacitación ciudadana y capacitación para el trabajo. Para la selección de los ámbitos y población de aplicación del PCP se consideraron las variables e indicadores siguientes (Cuadro 9).

\subsection{Modelo de Gestión del Programa Ciudadanía Plena}

EI MODELO DE GESTIÓN del PCP de acuerdo a González (2003: 45), se fundamenta en el apoyo y acompañamiento de la comunidad mediante la figu- 

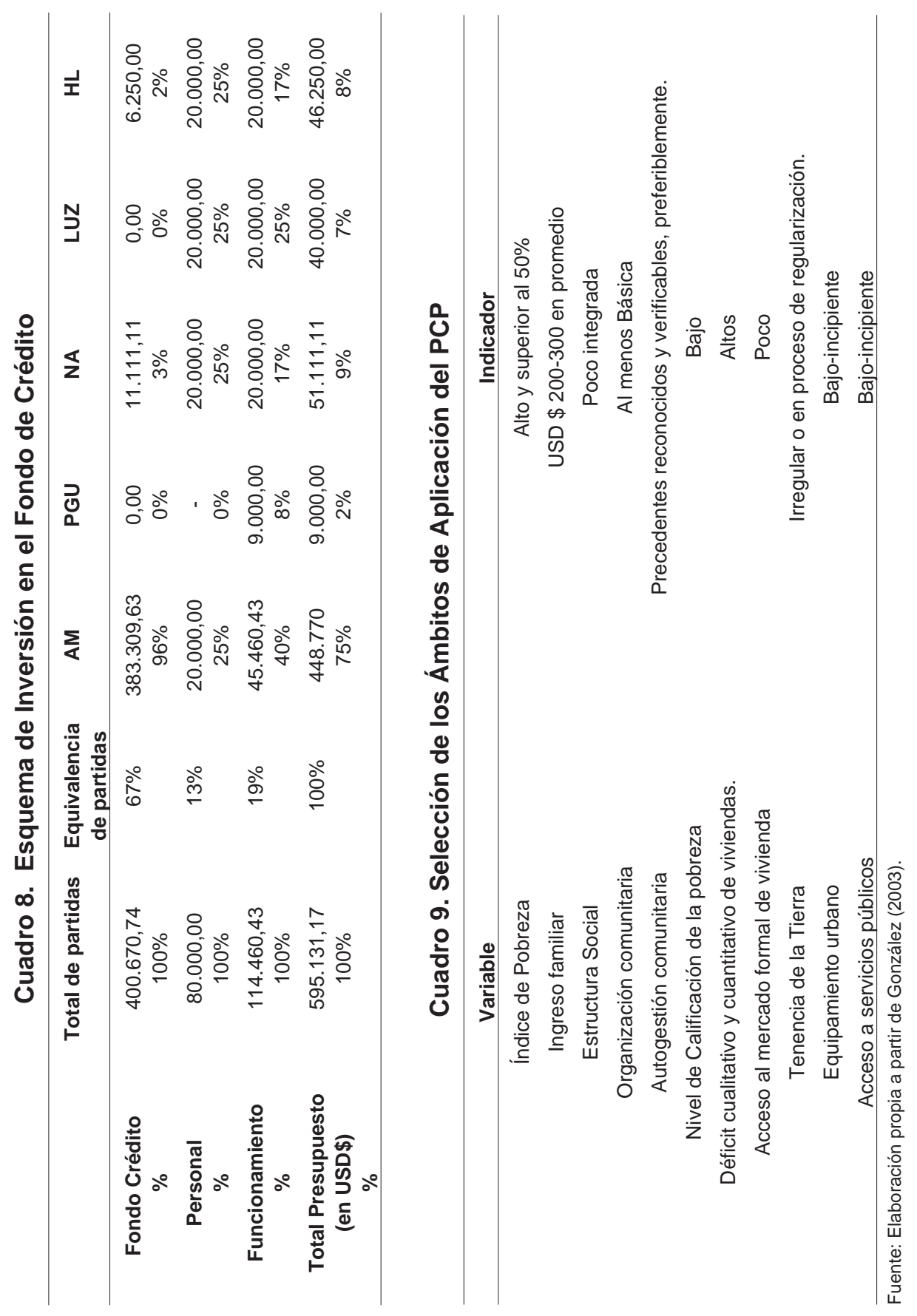
Estrategia de evaluación innovadora

Ferrer, Mercedes; Gómez, Nersa y Reyes, Ramón

ra de alianza y articulación de actores en una RED DE COMUNICACIÓN LOCAL ( $R C L)$, que actúa en cada una de las $\mathrm{Pa}$ rroquias (unidad política-territorial en la que se subdividen lo municipios en Venezuela). Las RCL tiene el propósito, según González de generar procesos deliberativos y de reflexión de las acciones concertadas en la Asamblea de la Comunidad.

La administración del PCP según González (2003) se realiza a través de una estructura organizativa que integra tres instancias, las cuales tienen funciones específicas como se expresa en el Cuadro 10.

4.4.1. Un modelo de gestión consorciada para superar la pobreza urbana

El diseño del un Modelo de Gestión, según Ferrer y Quintero (2002), para la formación de una política urbana bottom up (abajo arriba), requiere de una intervención urbana estratégica y participativa, que integre la gestión urbana + intervención social (Cuadro 11).

Este modelo de gestión genera nuevos métodos y prácticas urbanas que viabilizan una nueva cultura en el proceso de construcción de la ciudad. El objeto de este proceso es construir - en forma concertada y colectiva - la viabilidad política, institucional, social - cultural y financiera, en este caso del PCP. El proceso de viabilización tiene dos objetivos básicos, compatibilizar las expectativas de los diferentes actores sociales con las propuestas que se generen y, establecer nuevos patrones de conducta "ciudadanos plenos" y, una nueva cultura urbana, para inducir a la toma de decisión en forma compartida y colectiva (Ferrer y Quin- tero, 2002). En relación a la formación de una política bottom up, el modelo de gestión para Ferrer y Ávila (2000) asume la intervención urbana como proceso de negociación y gestión coordinada y continua entre diferentes actores, públicos, privados y asociativos para seleccionar por consenso vías para solucionar los problemas percibidos en el uso cotidiano de las ciudades, en este caso la pobreza urbana. La garantía de éxito del proceso propuesto se centra en movilizar la confianza activa, a través de la participación democrática y sinérgica de los actores ahora corresponsables de la ejecución del PCP.

\section{Diseño de la Estrategia de Evaluación}

Según Viñas (2002:9), la evaluación es una investigación objetiva y sistemática para emitir juicios de valor sobre una intervención pública, interpretando y analizando con métodos rigurosos la información recogida y/o producida especialmente. Su misión para Viñas es determinar la pertinencia, la eficacia, la eficiencia, el impacto, la calidad y la sostenibilidad de todas las actividades para ayudar a mejorar las actuaciones que están aun en marcha y en la planificación y ejecución de los programas Para evaluar el potencial de transformación del PCP y ante la inexistencia de métodos de evaluación específicos sobre el tema, se asumieron como antecentes los métodos para la evaluación de políticas públicas.

Según Barret (1998: 3), el propósito fundamental de la evaluación de políticas públicas es conocer la efectividad de la política en el cumplimiento de sus objetivos, que en términos operacionales 


\begin{tabular}{|c|c|c|c|}
\hline \multicolumn{4}{|c|}{$\begin{array}{c}\text { Cuadro } 10 \\
\text { Estructura organizativa para la gestión del PCP }\end{array}$} \\
\hline $\begin{array}{c}\text { Estructura } \\
\text { Organizativa }\end{array}$ & Actores & Funciones & Observaciones \\
\hline $\begin{array}{c}\text { Consejo de } \\
\text { Administración } \\
\text { (CA) }\end{array}$ & $\begin{array}{l}\text { Alcaldía Maracaibo } \\
\text { PGU-ALC / PNUD LUZ } \\
\text { Nuevo Amanecer- } \\
\text { CESAP, HÁBITAT } \\
\text { LUZ, IFAD-LUZ; } \\
\text { Comunidades } \\
\text { CECOSEZUL* }\end{array}$ & $\begin{array}{l}\text { Formulación de políti- } \\
\text { cas y pautas para la } \\
\text { planificación del PCP }\end{array}$ & $\begin{array}{l}\text { - El PGU-ALC mantie- } \\
\text { ne estrecha relación } \\
\text { con este nivel. } \\
\text { - Se reúne semanal- } \\
\text { mente. }\end{array}$ \\
\hline $\begin{array}{l}\text { Unidad de Gestión } \\
\text { (UG) }\end{array}$ & $\mathrm{CA}$ & $\begin{array}{l}\text { Brazo operativo del CA } \\
\text { y coordinador de la eje- } \\
\text { cución del PCP }\end{array}$ & $\begin{array}{l}\text { - La Alcaldía de Mara- } \\
\text { caibo coordina y están } \\
\text { incluidos todos los } \\
\text { ejecutivos del SAMI** } \\
\text { Maracaibo. }\end{array}$ \\
\hline $\begin{array}{l}\text { Asamblea de la } \\
\text { Comunidad (AC) }\end{array}$ & $\begin{array}{l}\text { Comunidad } \\
\mathrm{CA}+\mathrm{UG}\end{array}$ & $\begin{array}{l}\text { Instancia de decisión y } \\
\text { participación ciudada- } \\
\text { na, que establece: prio- } \\
\text { ridades, planes, pro- } \\
\text { yectos de cada comuni- } \\
\text { dad }\end{array}$ & $\begin{array}{l}\text { - Se relacionan en la } \\
\text { RCL. } \\
\text { - El CA + UG participan } \\
\text { en todas las AC para } \\
\text { que las políticas y ac- } \\
\text { ciones respondan a lo } \\
\text { acordado. }\end{array}$ \\
\hline
\end{tabular}

Fuente: Elaboración propia a partir de González (2003: 29-30).

* CECOSEZUL se incorporará próximamente. ${ }^{* *}$ Servicio Autónomo Microempresarial de Maracaibo.

se traduce en una serie de objetivos generales y específicos y medir la eficiencia de las políticas. Para este autor el fin último de las políticas es mejorar la calidad de vida. Para medir la eficiencia de las políticas se relacionan los inputs o recursos empleados y los resultados o impactos conseguidos. Para este autor es útil considerar el proceso de evaluación como un ciclo con distintas fases, cada una con propósitos y énfasis diferentes, en este sentido en el Cuadro 12 se relacionan las tres fases de evaluación ex-ante, durante y ex-post - con el propósito y las cuestiones principales y concretas de la evaluación.
De acuerdo a Barret (1998: 11), las aproximaciones a la evaluación de programas de desarrollo son de dos tipos: Análisis macro de arriba abajo (top down), que pretende extraer conclusiones sobre la efectividad de las intervenciones desde el análisis del conjunto de los patrones de cambio en el área o áreas en cuestión, del modo implícito o explicito que evalúa como ha cambiado un área y como hubiera cambiado en ausencia de la política, es decir, la cuestión contrafactual. El análisis micro o de abajo a arriba (bottom up), pretende construir el cuadro general de los impactos, agregando los efectos de los elementos constitutivos del paquete de políticas o política (Cuadro 13). 
Estrategia de evaluación innovadora

Ferrer, Mercedes; Gómez, Nersa y Reyes, Ramón

\begin{tabular}{|c|c|c|}
\hline \multicolumn{3}{|c|}{$\begin{array}{c}\text { Cuadro 11 } \\
\text { Modelo de Gestión del PCP }\end{array}$} \\
\hline Actividades & Objetivos & Resultados \\
\hline $\begin{array}{l}\text { EI PCP: Una alianza } \\
\text { estratégica } \\
\text { de actores sociales }\end{array}$ & $\begin{array}{l}\text { - Concretar una alianza entre } \\
\text { actores locales e internaciona- } \\
\text { les para ejecutar el PCP y en- } \\
\text { frentar la pobreza urbana. } \\
\text { - Fortalecer la alianza incluyen- } \\
\text { do otros actores. }\end{array}$ & $\begin{array}{l}\text { Firmada carta de Intención } \\
\text { en Florencia, Italia } 1997 \\
\text { Incorporación de nuevos ac- } \\
\text { tores al PCP }\end{array}$ \\
\hline $\begin{array}{l}\text { Construcción de } \\
\text { la visión compartida }\end{array}$ & $\begin{array}{l}\text { - Crear Red de Comunicación } \\
\text { Local (RCL), } \\
\text { - Organizar a los actores públi- } \\
\text { cos y asociativos en tres ins- } \\
\text { tancias con funciones especí- } \\
\text { ficas: el Consejo de Adminis- } \\
\text { tración, la Unidad de Gestión y } \\
\text { la Asamblea de la Comunidad. } \\
\text { - Crear el Consorcio. }\end{array}$ & $\begin{array}{l}\text { Creada la RCL, el CA, la UG y } \\
\text { la Asamblea de la Comuni- } \\
\text { dad }\end{array}$ \\
\hline $\begin{array}{c}\text { Implementación del Modelo } \\
\text { de Gestión: el Plan } \\
\text { de Acción }\end{array}$ & $\begin{array}{l}\text { - Coordinar las estrategias, ac- } \\
\text { ciones, responsabilidades y } \\
\text { recursos para ejecutar la } 1 \text { a } \\
\text { Fase de expansión del PCP. }\end{array}$ & $\begin{array}{l}\text { Se elaboró y ejecuto la } 1^{a} \text { eta- } \\
\text { pa del Plan y están en proce- } \\
\text { so las otras } 2 \text {. }\end{array}$ \\
\hline $\begin{array}{l}\text { Ejecución de una } \\
\text { Experiencia Piloto } \\
\text { - Proyecto } \\
\text { Vivienda Digna - }\end{array}$ & $\begin{array}{l}\text { - Mejorar el hábitat y la vivienda } \\
\text { a través del otorgamiento de } \\
\text { microcréditos. }\end{array}$ & $\begin{array}{l}\text { Se ejecutó la experiencia en } \\
\text { el Barrio Ma. Angélica de Lu- } \\
\text { sinchi de la parroquia Luís } \\
\text { Hurtado Higuera. Iniciado en } \\
1999 \text { todavía en ejecución }\end{array}$ \\
\hline
\end{tabular}

Fuente: Elaboración propia 2005, a partir de Ferrer y Quintero (2004) y González (2003: 45-46-49).

\section{Una Estrategia de Evaluación Innovadora (EEi)}

\subsection{Enfoque y Método de la EEi}

Considerando el objeto de esta investigación, evaluar e Modelo de Gestión del PCP a través de una EEi para conocer el potencial de transformación del Programa en política urbana inteligente y, después de la revisión documental realizada se delimitaron los criterios e indicadores relacionados con el tema de estudio a partir de la consideración de las res- puestas a las preguntas: ¿Cómo calibrar el grado de implicación efectiva de los actores en el PCP y su potencial de inclusión en sus agendas como proyecto de vida de las instituciones participantes? ¿Cuál es el grado de replicabilidad del modelo en otras comunidades? Así mismo las hipótesis del EEi se formulan mediante las preguntas, ¿A mayor capacitación, más participación e implicación de ciudadanos plenos, mayor compromiso en la gestión local? ¿Una calibración de la implicación institucional y ciudadana de un $40 \%$ a través de la EEi o modelo de 
Cuadro 12

Fases de evaluación de una política pública

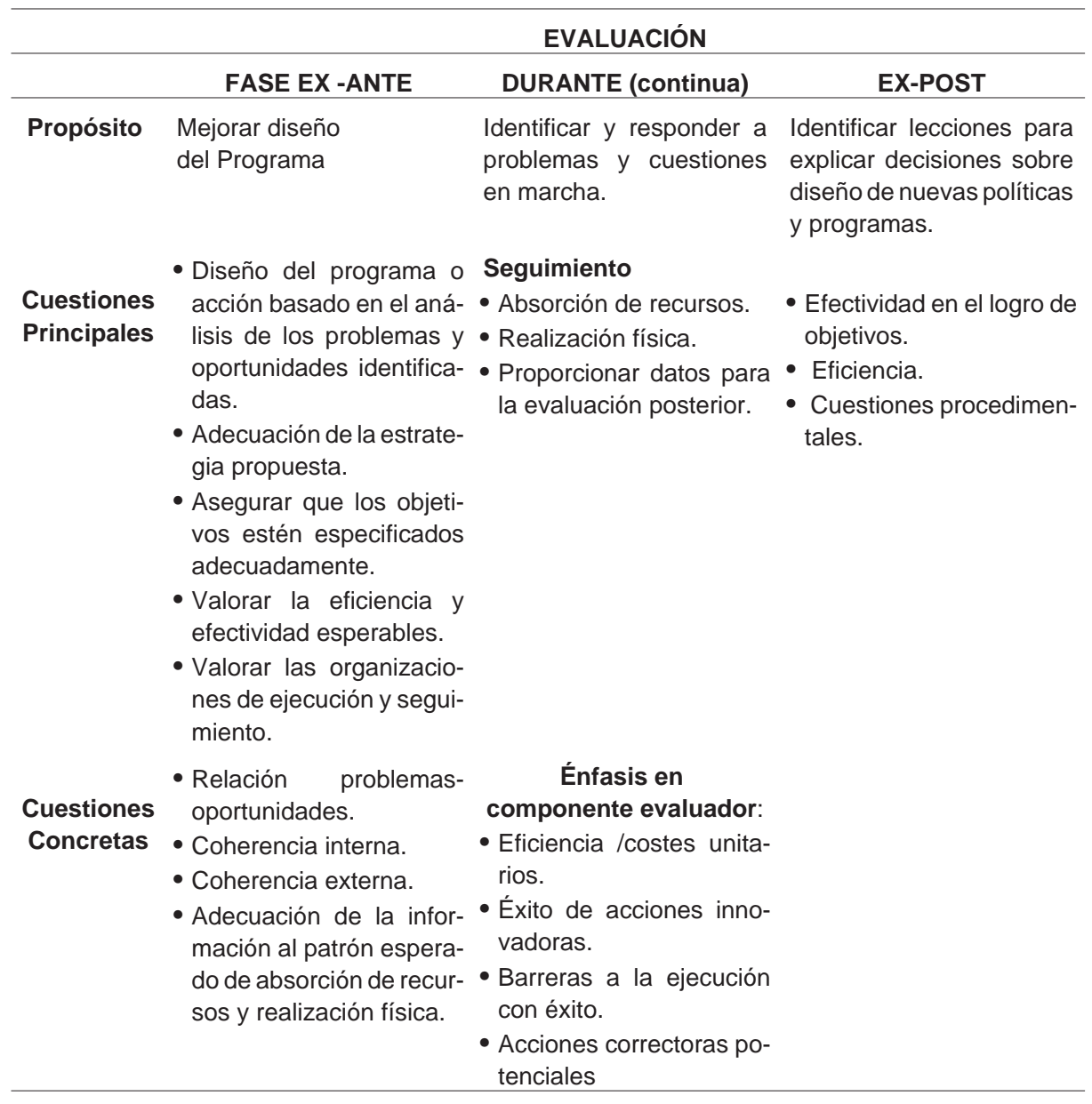

Fuente: Elaboración propia a partir de Barret (1998: 8).

evaluación participativa, incidirá significativamente en la mejora del Modelo de Gestión del PCP y en su transformación en política pública? ¿La formación y capacitación ciudadana para la gestión del hábitat y la formación de ciudadanía plena incidirá en la disminución de la pobreza urbana? ¿La evaluación de los atribu- tos de ciudadanía plena, permitirá mejorar el modelo de gestión tendente a superar la pobreza urbana? ¿Es posible caracterizar los atributos de un ciudadano pleno y una ciudadanía plena para Venezuela, el estado Zulia y Maracaibo?

La EEi asume la metodología de Evaluación de Gestión (EG), porque se 
Estrategia de evaluación innovadora

Ferrer, Mercedes; Gómez, Nersa y Reyes, Ramón

Cuadro 13

Aproximación macro y micro a la evaluación de programas

\begin{tabular}{|c|c|c|}
\hline Elementos Clave & $\begin{array}{c}\text { Aproximación Macro } \\
\text { (Top down) }\end{array}$ & $\begin{array}{c}\text { Aproximación Micro } \\
\text { (Bottom up - hacia una PUI) }\end{array}$ \\
\hline Característica Global & $\begin{array}{l}\text { - Impactos valorados a partir del } \\
\text { cambio global en relación a algún } \\
\text { escenario "contrafactual". }\end{array}$ & $\begin{array}{l}\text { - Estimaciones de impactos a par- } \\
\text { tir de agregación de efectos de } \\
\text { los proyectos individuales. }\end{array}$ \\
\hline \multirow[t]{2}{*}{$\begin{array}{l}\text { Aproximaciones } \\
\text { Alternativas }\end{array}$} & - Modelización. & $\begin{array}{l}\text { Marco de referencia: } \\
\text { - Cambio real = Suma bruta. } \\
\text { - Suma bruta menos desplaza- } \\
\text { mientos = Suma neta. } \\
\text { - Suma neta más efectos secun- } \\
\text { darios = Impacto total. }\end{array}$ \\
\hline & Análisis comparado: & Análisis de seguimiento: \\
\hline $\begin{array}{l}\text { Analisis Comparado } \\
\text { y de Seguimiento }\end{array}$ & $\begin{array}{l}\text { - Comparación con tendencias } \\
\text { más amplias. } \\
\text { - Análisis de modificación y repar- } \\
\text { to de los cambios de actuación a } \\
\text { lo largo del tiempo. } \\
\text { - Comparación con áreas de con- } \\
\text { trol. } \\
\text { - Modelización estadística basada } \\
\text { en periodos con la política funcio- } \\
\text { nando y sin funcionar. }\end{array}$ & $\begin{array}{l}\text { - Encuestas a beneficiarios indivi- } \\
\text { duales. } \\
\text { - Grupos de discusión. } \\
\text { - Información sobre los no benefi- } \\
\text { ciarios. } \\
\text { - Discusiones contextuales con } \\
\text { expertos. } \\
\text { - Valoración y juicio profesional. } \\
\text { - Encuestas a mayor escala. } \\
\text { - Análisis de datos. } \\
\text { - Discusión con gestores y socios } \\
\text { del Programa. }\end{array}$ \\
\hline
\end{tabular}

Fuente: a partir de Barret (1998: 19).

adapta mejor a los objetivos de la investigación. La EG es un ejercicio de valoración de acciones, procesos y resultados, desarrollados por los organismos de gestión de acuerdo al rol asignado y al enfoque de gestión desarrollado. Su objetivo es evaluar el diseño, gestión y resultados de los programas públicos, proporcionando información para apoyar la gestión de los programas, el proceso de asignación de recursos y sobre todo, identificar mejoras y acciones que deben ser puestas en práctica para maximizar los beneficios del PCP. Esta metodología de evaluación responde a las condiciones vinculadas al origen y antecedentes del proceso de diseño, marco institucional-legal, contexto político, estrategias de implantación, desempeño Institucional, participación de los actores; todo lo cual permite identificar los Indicadores de Gestión y conocer los principales logros del Plan o Modelo de Gestión implantado.

La EG precisa el establecimiento de criterios que tienen un peso porcentual dependiendo de su importancia dentro de la gestión, se validan y verifican a través de mecanismos de valoración sobre el nivel de desarrollo en que se encuentra el criterio evaluado. Este nivel podía ser: Exitoso, 
Bueno, Satisfactorio, en Evolución y Deficiente. Este método se complementa con otra metodología que maneja la evaluación como herramienta para una gestión pública orientada a resultados, la cual considera los siguientes criterios:

1. Direccionamiento estratégico definido: Conjunto de acciones que orientan a la organización, comprende la Misión, Visión, Objetivos Estratégicos y Principios.

2. Capacidad de adaptación a las dinámicas del proyecto: acciones emprendidas por la organización para adecuarse y responder a las condiciones operativas, financieras y técnicas del programa y del contexto donde se ubica, sin desvirtuar su direccionamiento estratégico.

3. Promoción de la participación comunitaria: forma en que la institución trabaja para lograr que la comunidad beneficiaria del programa participe en todas las fases del ciclo del proyecto y desarrolle acciones sostenibles alrededor del mismo.

4. Cumplimiento y desarrollo de estándares del Programa: es la forma como la EG desarrolla dentro del programa los modelos, formatos y procedimiento estandarizados, en forma oportuna y adecuada y como los ha incorporado a su gestión.

5. Procesos de seguimiento y monitoreo: conjunto de acciones desarrolladas por la institución para asegurar el desarrollo de las acciones de acuerdo a la programación establecida, impulsando el ajuste y modelando el proceso cuando los resultados no son satisfactorios.
6. Aprendizaje organizacional: grado en que la experiencia permite: constituir equipos, mejorar la capacidad técnica, las estrategias de intervención, la referenciación y la transferencia.

7. Comunicación y difusión de las acciones y proyectos: medios y acciones emprendidas para divulgar sus acciones y su gestión dentro del Programa.

8. Documentación y sistematización: grado en que la organización documenta y sistematiza su experiencia (metodologías, estrategias y aprendizajes del proyecto) a fin de permitir su aplicación sistemática y organizada, es decir, de forma planeada y siguiendo procedimientos prediseñados y probados; evaluada y mejorada, en otros contextos, áreas, regiones o experiencias de forma exitosa.

9. Reconocimiento y Visibilidad: grado en que la experiencia y gestión ha sido conocido y valorado públicamente y por tanto aporta a la visibilidad de los proyectos que desarrolla, lo que se refleja en la aparición en medios de comunicación, el uso de páginas web y otros mecanismos para la información pública que permite procesos de referenciación.

10. Identificación y Establecimiento de Alianzas: grado en que los resultados de la experiencia promueven la identificación, generación y mantenimiento de alianzas con distintos actores del desarrollo regional y local, así como el grado en que potencie el trabajo en red entre estos actores.

\subsection{Metodología del EEi}

El objetivo de la EEi es diseñar y aplicar una metodología para evaluar y 
Estrategia de evaluación innovadora

Ferrer, Mercedes; Gómez, Nersa y Reyes, Ramón

contribuir a mejorar el MODELO DE GESTIÓN del PROGRAMA CIUDADANÍA PLENA (PCP), mediante una estrategia innovadora para calibrar la participación institucional y ciudadana efectiva y la valoración de atributos que caracterizan un ciudadano pleno: Grado de compromiso: decisiones y acuerdos tomadosejecutados $y / 0$ proyectos formulados $y$ ejecutados; Grado de Responsabilidad -pago de préstamos, asistencia a cursos, entre otros-; Niveles de solidaridad familiar y comunitaria; Nivel de participación en el seguimiento del ciclo de vida de los proyectos; Número de préstamos solicitados y cancelados por familia y grupo organizado. El propósito básico es conocer el potencial transformador del PCP en política urbana inteligente e incentivar a autoridades municipales, a grupos comunitarios, ONG's y otros actores a tomar decisiones más equitativas, económicamente viables y socialmente coherentes con las necesidades de la población. De esta forma se concibe la promoción de una Ciudadanía Plena como proceso sociocultural y político de construcción de capacidades para superar la pobreza urbana (González, 2003) y en este contexto, la gestión creativa de microcréditos como imán para lograr la capacitación ciudadana. Desde esta perspectiva, los objetivos de la EEi son los siguientes:

- Diseñar y aplicar instrumentos de evaluación participativa ex-post y monitoreo.

- Elaborar indicadores que permitan calibrar el proceso de construcción de CIUDADANÍA PLENA, útiles para tomar decisiones sobre el Modelo de Gestión del PCP.
- Estudiar la viabilidad política, social, institucional y financiera del PCP y del Modelo de Gestión para evaluar el potencial transformador del PCP en política pública.

- Difundir los resultados de la EEi dando cuenta de las fortalezas y limitantes metodológicas y de la coherencia entre teoría y práctica, para fortalecer el PCP.

El método de evaluación propuesto se estructura en cuatro fases. Fase 1: REVISIÓN DOCUMENTAL para contextualizar el tema - pobreza urbana y ciudadanía plena a nivel latinoamericano y venezolano -; Fase 2: ANÁLISIS COMPARADO de casos de estudios para garantizar una mejor comprensión del PCP y, conocer diferentes metodologías/modelos de evaluación aplicadas, los modelos de gestión utilizados (actores participantes, alianzas, planes y proyectos) y las teorías que los fundamentan, para identificar las variables a ser incorporadas en la EEi que permitirán calibrar la participación ciudadana y los indicadores de evaluación correspondientes. Fase 3: DISEÑO DE LA EEi o Modelo de Evaluación Participativa (MEP). Fase 4: APLICACIÓN DEL EEi al PCP, análisis de resultados, conclusiones y recomendaciones (Cuadro 14).

Los resultados de la aplicación de la EEi o MEP permitirán identificar los cambios en las relaciones de poder entre los actores centrales del ámbito local y la capacitación ciudadana contextualizada dentro de la realidad local y orientada a fortalecer redes sociales para el cambio social y por ende la sostenibilidad para el desarrollo local. Igualmente, se espera a largo plazo un impacto positivo en la equidad en oportunidades y servicios y en la 
Revista Venezolana de Gerencia, Año 11, No. 35, 2006

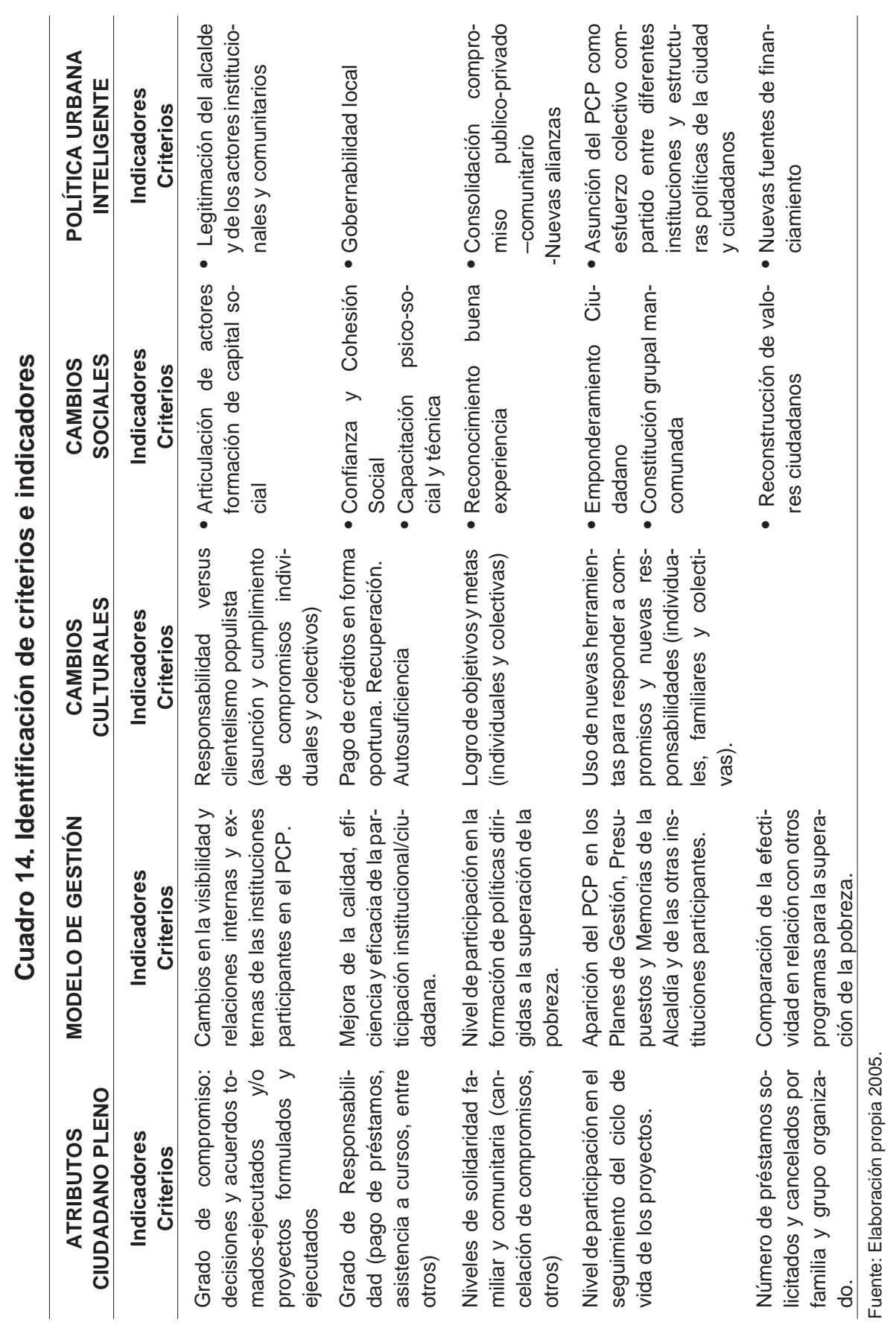


Estrategia de evaluación innovadora

Ferrer, Mercedes; Gómez, Nersa y Reyes, Ramón

calidad de vida de la población sujeto de esta iniciativa (De Salazar y Díaz, 2004).

\subsection{Potencial Transformador del PCP en Política Urbana Inteligente}

Para evaluar el potencial transformador del PCP en política urbana inteligente (PUI), la Estrategia de Evaluación Innovadora articula Política Urbana Inteligente (PCP) y el Modelo de Gestión para reducir la pobreza urbana (EEi = Política Urbana Inteligente (PCP) + Modelo de Gestión < Pobreza Urbana). La estrategia trenza las propuestas de Brugué y Gomà y Gomà y Subirats (1998:28 y, 1999:389) y Subirats (1989), referidas al proceso de análisis y evaluación de políticas públicas.

En este sentido, la EEi se basa en el análisis empírico de políticas públicas y sigue el modelo de fases o procesos, en el cual las políticas públicas recorren un itinerario no estrictamente lineal, con interacciones complejas entre fases pero de lógica secuencial. El recorrido, siguiendo a estos autores se fragmenta en tres grandes fases, en la primera, se constata si el PCP responde a un problema prioritario compartido y el acceso del tema en la agenda pública, en la segunda, se analiza el proceso de negociación entre alternativas de actuación para la toma de decisión e, implicación de los actores en la gestión del PCP, en la tercera fase, y en la cuarta fase, se evalúa el Modelo de Gestión del PCP, a partir de los indicadores seleccionados que posibilitan medir el logro de los objetivos del PCP (Cuadro 15).

\section{Conclusiones}

Como conclusiones de esta primera fase de la investigación, cuyo objetivo era diseñar una estrategia de evaluación innovadora (EEi) para reconocer el potencial de transformación del PCP en política urbana inteligente, se pueden mencionar las siguientes:

En relación a la Estrategia de Evaluación propuesta (EEi):

1. En la revisión documental realizada destaca la ausencia de metodologías de evaluación dirigidas a la consecución del objetivo de la investigación, conocer el potencial de transformación de un programa de intervención social en politica publica. La propuesta EEi constituye por tanto, un aporte metodológico dirigido a superar este vació.

2. La estrategia propuesta (EEi) permitirá:

- La evaluación del grado de apropiación del PCP como esfuerzo colectivo.

- La valoración de los objetivos logrados dirigidos a construir ciudadanos plenos, mejorar el hábitat precario y superar la pobreza urbana en Maracaibo.

- La propuesta de acciones para garantizar la permanencia del PCP en la agenda de los actores interesados e involucrados.

Estos indicadores son clave para establecer el potencial de transformación del Programa de Ciudadanía Plena en Política Urbana Inteligente (PUI).

En relación a la transformación del PCP en Política Urbana Inteligente:

3. Se propone el concepto de Política Urbana Inteligente que además de ser bottom up o de abajo arriba, construye ciudadanía plena al emponderar a los ciudadanos, legitima al alcalde por desempeño-resultados y incrementa la gobernabilidad local. 


\begin{tabular}{|c|c|c|c|c|}
\hline \multicolumn{5}{|c|}{$\begin{array}{l}\text { Cuadro } 15 \\
\text { Evaluación de pcp como política pública }\end{array}$} \\
\hline \multirow{3}{*}{$\begin{array}{l}\text { DIMENSIONES } \\
\text { EVALUATIVAS }\end{array}$} & \multicolumn{4}{|c|}{ FASES DE EVALUACIÓN DE POLÍTICAS } \\
\hline & FASE 1 & FASE 2 & FASE 3 & Fase 4 \\
\hline & $\begin{array}{l}\text { Respuesta a } \\
\text { problema e } \\
\text { inclusión en } \\
\quad \text { agenda }\end{array}$ & $\begin{array}{l}\text { Proceso de } \\
\text { Implicación } \\
\text { Actores }\end{array}$ & Formulación MG & $\begin{array}{l}\text { Evaluación } \\
\text { MG }\end{array}$ \\
\hline $\begin{array}{l}\text { Simbólica: ana- } \\
\text { liza la construc- } \\
\text { ción estrategias } \\
\text { discursivas y } \\
\text { marcos cogniti- } \\
\text { vos. }\end{array}$ & $\begin{array}{l}\text { Verificación si el } \\
\text { PCP responde a } \\
\text { problema priori- } \\
\text { tario/incluido en } \\
\text { la agenda de los } \\
\text { actores implica- } \\
\text { dos. }\end{array}$ & & & \\
\hline $\begin{array}{l}\text { De Estilo: se ob- } \\
\text { servan las actitu- } \\
\text { des, disposicio- } \\
\text { nes y estrategias } \\
\text { de los actores }\end{array}$ & & $\begin{array}{l}\text { Análisis del pro- } \\
\text { ceso de negocia- } \\
\text { ción/implicación } \\
\text { de actores en el } \\
\text { PCP }\end{array}$ & & \\
\hline $\begin{array}{l}\text { Sustantiva: veri- } \\
\text { fica los conteni- } \\
\text { dos y grandes } \\
\text { opciones de fon- } \\
\text { do }\end{array}$ & & & $\begin{array}{l}\text { Análisis del pro- } \\
\text { ceso de formula- } \\
\text { ción del Modelo } \\
\text { Gestión }\end{array}$ & \\
\hline $\begin{array}{l}\text { Operativa: com- } \\
\text { paración resulta- } \\
\text { dos versus objeti- } \\
\text { vos }\end{array}$ & & & & $\begin{array}{l}\text { Evaluación del } \\
\text { Modelo Gestión } \\
\text { PCP/indicadores } \\
\text { y objetivos }\end{array}$ \\
\hline
\end{tabular}

Fuente: Elaboración propia 2005 a partir de Brugué y Gomà, 1998:28 y, Gomà y Subirats, 1999:389.

4. La transformación del PCP en política urbana inteligente viabilizará la emergencia de una nueva "ciudadanía" fundada en valores y mejoras en la capacidad de gestión local -coordinación transversal multiactoral y multidisciplinar-, como vía hacia un Maracaibo sostenible y la superación de la pobreza urbana.

5. EI PCP como nueva práctica de gestión necesita para su continuidad en el tiempo o proyecto de vida (ética públi- ca) de los actores implicados, un acuerdo social y participación sostenida, que amplié la gobernabilidad y garantice su legitimidad.

6. El PCP apunta hacia la transformación de la cultura urbana y el desarrollo de una nueva institucionalidad, promoviendo espacios sociales en que los individuos coproducen y cogestionan responsablemente actividades en respuesta a sus necesidades. 
Estrategia de evaluación innovadora

Ferrer, Mercedes; Gómez, Nersa y Reyes, Ramón

7. La creación del SAMI es un indicador visible del potencial de transformación del PCP en Política Urbana Inteligente.

¿Cómo mantener la motivación y el interés del conjunto de actores para que sigan participando? Los actores involucrados deben COMPARTIR tanto la visión del PCP, en un ambiente participativo-deliberativo donde todos ganan, como los aspectos siguientes:

- El problema o necesidad que dio origen el PCP.

- Los objetivos planteados y el programa de actuación y sus plazos.

- El Modelo de Gestión propuesto.

- Las responsabilidades asignadas en el marco de los valores y principios rectores del Programa y

- Los resultados obtenidos que servirán para evaluar el avance y realizar los ajustes necesarios.

En este contexto será fundamental destacar los resultados, que permitan reforzar el interés en el PCP, referidos a su utilidad para la sociedad, destacando la formación de capital social y político, la consolidación del capital físico mediante la mejora de las viviendas y la creación de empleo, conectado con el objetivo de romper el círculo negativo de la pobreza urbana y lograr un hábitat sostenible. A través de la EEi será posible fortalecer la permanencia del PCP en agenda garantizando su contribución en la superación de la pobreza en Maracaibo y viabilizando su replicabilidad en otras ciudades del país.

\section{Referencias Bibliográficas}

Arroyo, Daniel (1997). Estilos de Gestión y Políticas Sociales Municipales en
Argentina. Hacia un nuevo modelo de gestión local. Universidad Católica de Córdoba, Oficina de publicaciones del CBC. Argentina.

Barret, George (1998). Evaluación cuantitativa y cualitativa de Programas Regionales: ¿Cómo estas prácticas pueden ser una función integrante de la gestión de la ciudad global. La ciudad global: ¿Cómo Gestionarla? Madrid, España.

Borja, Jordi (2004). "Los desafíos del territorio y los derechos de la ciudadanía". www. Lafactoríaweb.com/artículos/borja17.htm. Consultado 12 de Julio 2005.

Brugué, Quim y Gomà, Ricard (1998). Gobiernos locales y políticas públicas. Bienestar social, promoción económica y territorio. Editorial Ariel S.A. Barcelona, España.

Cunill Grau, Nuria (1997). Repensando lo público a través de la sociedad. Nueva Sociedad. Caracas, Venezuela.

Campbell, Tim (2005). "Ciudades: la nueva frontera". www. bancomundial. org/temas/cities/. Consultado 3 de Julio 2005.

De Salazar, Ligia y DÍAZ Constanza (2004). "Enfrentando el reto de la evaluación: Evaluación Participativa de Municipios y Comunidades Saludables". Colombia. www. prepsal uipes.cedetes.org/archivos/ Evaluación Participativa de Municipios y Común. PDF Consultado 04.03.2005.

España, Luís Pedro (2004). “¿Qué hacer para que los pobres no sean más pobres?" Conciencia Activa 21. No. 5 Extraordinario. Julio. Caracas: Fundación Conciencia Activa.

España, Luis Pedro (2006). "Las cifras de la pobreza en Venezuela". En SIC No. 682, Año LXIX, marzo. Caracas. Venezuela.

Ferrer, Mercedes (2003). Políticas Urbanas en el Gobierno Local. Del plan al 
gobierno por políticas. Tesis Doctoral. Facultad de Ciencias Jurídicas y Políticas. Universidad del Zulia. Maracaibo, Venezuela.

Ferrer, Mercedes y Quintero, Carolina (2002). "Realizando lo imaginado. La formación de una política urbana desde la investigación universitaria". Venezolana de Gerencia Ano 4 No. 20, Octubre - Diciembre. Astro Data S A. Maracaibo, Venezuela.

Ferrer; Mercedes y Ávila, Nancy (2000). "Construir la ciudad: un paradigma de gestión urbana. Venezolana de Gerencia". Año 5. No. 10. Astro Data S A. Maracaibo, Venezuela.

Ferrer, Mercedes; Quintero, Carolina, Perozo, Ma. Eugenia; Morón, Ceilen (2005). Del Archipiélago a la Fusión Territorial. Hacia una gestión urbana sustentable en Maracaibo, Venezuela. Territorios No. 14. Febrero-Julio. Universidad de los Andes. Bogotá, Colombia.

Franchini Teresa y Dal Cin, Adriana (2000), "Indicadores urbanos y sostenibilidad. Hacia la definición de un umbral de consumo sostenible de suelo". Ciudad y Territorio y Estudios Territoriales, XXXII (123). MOPU. Madrid, España.

Gomà, Ricard, Subirats, Joan -coords- (1999). Políticas Públicas en España. Contenidos, redes de actores y niveles de gobierno. Editorial Ariel S.A. Barcelona, España.

González, Marina (2003). Gestión Urbana participativa en Maracaibo. Venezuela. "Ciudadanía Plena". Un mecanismo de superación de la pobreza. PGU del PNUD, LUZ-CESAP, Fundación Hábitat-LUZ, Alcaldía de Maracaibo. Venezuela.

Herzer, Hilde y Pedro, Pírez (1993). Gestión urbana en ciudades intermedias de América Latina. Nairobi. CNUAH HABITAT.
Johannisson, Bengt; Karlsson, Charlie; Storey, David (1993). Designing supportive contexts for emerging enterprises. Small Business Dynamics. International, National and Regional Dynamics, Routledge. London and New York, Estados Unidos de America.

Montagut, Teresa (2000). Política Social. Una introducción. Editorial Ariel. Barcelona, España.

Ramos, Aldo (2002). "La sustentabilidad en las ciudades del tercer mundo". www.astrolabio.net/ planeta/ artículos/ 102617182633719. Consultado 07/ 03/2004.

REINGENIERIA DE LA GESTIÓN MUNICIPAL, QUITO. 2004. www.reingenieriagestionmunicipal.htm. Consultado 07/05/ 2005.

Spinelli, Graciela Hilda (2001). La descentralización y la participación ciudadana en la gestión local. Los limites de la globalización a la democracia http:// www.ubiobio.cl/cps/articulo/doc/p18. 4.htm Consultado 07/05/ 2005

Subirats, Joan (1989). Análisis de Políticas Públicas y eficacia de la administración. Instituto Nacional de Administración Pública (INAP). Madrid, España.

Ugalde, Luís; España, Luís Pedro et al (2004). Detrás de la pobreza. Universidad Católica Andrés Bello. Asociación Civil para la Promoción de Estudios Sociales. Caracas, Venezuela.

Viñas, Verónica (2002). "Descripción y análisis de la teoría sobre el seguimiento y evaluación aplicable a las actuaciones cofinanciadas por Fondos Europeos". En, Gestión y Análisis de Políticas Publicas (GAPP) No. 25 septiembre-diciembre. Ministerio de Administraciones Públicas. Madrid España. 